\title{
IMPLEMENTASI RESTFUL API PADA PENGEMBANGAN APLIKASI IF-KU BERBASIS ANDROID
}

\author{
1Fitrah Amalia, ${ }^{2}$ I Wayan Agus Arimbawa, ${ }^{3}$ Royana Afwani \\ 1,2,3Program Studi Teknik Informatika, Fakultas Teknik, Universitas Mataram. \\ Jl. Majapahit 62, Mataram, Lombok, NTB-INDONESIA. \\ 1fitrahamalia971995@gmail.com,2royana@unram.ac.id,3arimbawa@unram.ac.id
}

\begin{abstract}
The Informatics Engineering Study Program (PSTI) is one of the study programs at the University of Mataram. Currently at PSTI various information systems have been running for the needs of students. The problem that occurs is the information were accessed through a web browser with a different address. In overcoming problems that have been described, a system is needed that can provide information in one system. In connection with the availability of the Academic Information System (SIA) and Fingerprint system on PSTI that is equipped with an API with the REST method, so the data on SIA and Fingerprint can be displayed on the system to be developed. In order to the system that has been owned by PSTI can be displayed by other systems using web sevice. Therefore, an Android-based IF-application will be developed which implements a restful API. This system were used the Codeigniter to build a web services while Ionic frameworks to build mobile applications. Based on black box testing the system have been done well, while the testing using the MOS method shows that the average rating of respondents is $84.83 \%$.
\end{abstract}

Key words: REST API, web service, mobile, Ionic, Codeigniter

\begin{abstract}
Abstrak
Program Studi Teknik Informatika (PSTI) adalah salah satu program studi di Universitas Mataram. Saat ini di PSTI berbagai sistem informasi telah berjalan untuk kebutuhan siswa. Masalah yang terjadi adalah informasi itu diakses melalui browser web dengan alamat yang berbeda. Dalam mengatasi masalah yang telah dideskripsikan, diperlukan suatu sistem yang dapat memberikan informasi dalam satu sistem. Sehubungan dengan ketersediaan Sistem Informasi Akademik (SIA) dan sistem Sidik Jari pada PSTI yang dilengkapi dengan API dengan metode REST, sehingga data tentang SIA dan Sidik Jari dapat ditampilkan pada sistem yang akan dikembangkan. Agar sistem yang telah dimiliki oleh PSTI dapat ditampilkan oleh sistem lain menggunakan layanan web. Oleh karena itu, aplikasi IF berbasis Android akan dikembangkan yang mengimplementasikan API yang tenang. Sistem ini menggunakan Codeigniter untuk membangun layanan web sementara kerangka ionik untuk membangun aplikasi mobile. Berdasarkan pengujian black box sistem telah dilakukan dengan baik, sedangkan pengujian menggunakan metode MOS menunjukkan bahwa peringkat rata-rata responden adalah $84,83 \%$.
\end{abstract}

Kata kunci : REST API, web service, mobile, Ionic, Codeigniter

\section{Pendahuluan}

Di lingkungan kampus, informasi akademik merupakan kebutuhan yang sangat penting bagi para mahasiswa. Berbagai informasi yang dibutuhkan mahasiswa antara lain informasi nilai, Indeks Prestasi per semester, Indeks Prestasi
Kumulatif, total Satuan Kredit Semester saat ini, total Satuan Kredit Semester lulus, mata kuliah, absensi, dan informasi perkuliahan.

Disisi lain di Program Studi Teknik Informatika (PSTI) Universitas Mataram telah berjalan berbagai sistem informasi. Sistem-sistem tersebut antara lain sistem informasi nilai, Indeks Prestasi 
per semester, Indeks Prestasi Kumulatif, total Satuan Kredit Semester saat ini, total Satuan Kredit Semester lulus, mata kuliah yang disebut Sistem Informasi Akademik (SIA) dan sistem informasi kehadiran dosen dan staff yang disebut sistem Fingerprint. Sistem Fingerprint yaitu sistem kehadiran dengan sidik jari. Permasalahan yang terjadi adalah informasi-informasi tersebut diakses melalui web browser dengan alamat yang berbeda-beda.

Dalam mengatasi masalah yang telah dijabarkan di atas, maka dibutuhkan sistem yang dapat memberikan informasi nilai, Indeks Prestasi per semester, Indeks Prestasi Kumulatif, total Satuan Kredit Semester saat ini, total Satuan Kredit Semester lulus, mata kuliah sekaligus informasi kehadiran dosen dan staff serta informasi perkuliahan di dalam satu sistem.

Dalam implementasi sistem ini tentu data yang dibutuhkan adalah data nilai, Indeks Prestasi per semester, Indeks Prestasi Kumulatif, total Satuan Kredit Semester saat ini, total Satuan Kredit Semester lulus, mata kuliah, mahasiswa, dosen yang terdapat pada SIA dan data kehadiran dosen dan staff yang terdapat pada sistem Fingerprint. Sehubungan dengan tersedianya SIA dan Fingerprint pada PSTI yang dilengkapi API dengan metode REST, maka data yang diolah dan disimpan pada SIA dan Fingerprint dapat ditampilkan pada sistem yang akan dikembangkan. Agar data SIA dan Fingerprint dapat ditampilkan pada sistem yang dikembangkan maka diperlukan sebuah solusi untuk integrasi antar sistem. Oleh karena itu digunakan web sevice agar sistem yang sudah di miliki PSTI dapat ditampilkan oleh aplikasi lain.

Seiring dengan berkembangnya teknologi informasi, banyak teknologi baru yang muncul, salah satunya teknologi mobile berbasis Android yang memudahkan pengguna dalam mengakses informasi yang dibutuhkan. Perkembangan teknologi mobile berbasis Android di lingkungan kampus diharapkan mampu meningkatkan layanan sistem informasi akademik. Dengan kelebihan teknologi mobile berbasis Android seperti adanya fitur notifikasi yang sangat informatif, maka pengembangan sistem informasi akademik PSTI berbasis mobile penting untuk dilakukan agar memudahkan dan memenuhi kebutuhan mahasiswa akan informasi yang cepat dan akurat.

Teknologi Ionic merupakan sebuah framework open source yang dikembangkan untuk membangun aplikasi mobile dengan HTML5, CSS, dan Angular.js [1]. Ionic framework memiliki fitur yang lengkap dan user interface yang menarik, selain itu Ionic framework menggunakan teknologi web terbaru yaitu Angular.js dan Cordova, dengan memanfaatkan teknologi tersebut penggunaan Ionic framework menjadi lebih maksimal.

Berdasarkan uraian di atas, maka pada tugas akhir ini penulis akan mengimplementasikan RESTful API pada pengembangan Aplikasi IF-ku berbasis Android dan terintegrasi dengan SIA dan Fingerprint yang bertujuan memberi kemudahan bagi mahasiswa untuk mengetahui informasiinformasi akademik secara real-time sehingga penyampaian informasi menjadi optimal.

\section{TINJUAN PUSTAKA}

Pembuatan REST Service SIMPEG API di Kantor Walikota Bogor. Pembuatan REST Service SIMPEG API di Kantor Walikota Bogor merupakan solusi agar pihak internal maupun eksternal dapat menggunakan data kepegawaian Pegawai Negeri Sipil Kota Bogor dengan mudah dan termonitor. Selain itu, dengan adanya SIMPEG API ini memberi jalur pengaksesan data kepegawaian yang telah dibatasi oleh pihak BKPP Kota Bogor, sehingga pihak BKPP Kota Bogor dapat menyediakan keperluan eksternal tanpa memberikan akses langsung terhadap basis data BKPP Kota Bogor [2].

Aplikasi Mobile Sistem Informasi Akademik Berbasis Android pada SMKN 1 Pangkalpinang. Tujuan dari penelitian ini untuk menghasilkan karya nyata yang dapat memberi kemudahan dalam mendapatkan informasi dari pihak sekolah khususnya Sekolah Menengah Kejuruan Negeri 1 Pangkalpinang. Dimana orang tua murid tidak perlu repot datang kesekolah untuk mengetahui informasi (nilai raport,absensi dan pengumuman), dengan Aplikasi Sistem Informasi Akademik Berbasis Android ini, maka penyampaian informasi akademik sekolah kepada orang tua dan siswa-siswi yang bersangkutan akan lebih mudah, cepat dan efektif, jika dibandingkan dengan menggunakan cara manual [3].

Rancang Bangun Aplikasi Pengingat Jadwal Dan Tugas Kuliah Berbasis Android. Tujuan dari penelitian ini untuk membuat aplikasi pencatat jadwal dan pengingat tugas atau agenda mahasiswa agar mahasiswa bisa menjalankan aktivitasnya secara tepat dan terjadwal. Aplikasi tersebut nantinya menggunakan nama "My Daily". Aplikasi akan menampilkan jadwal, tugas, dan informasi lainnya yang diharapkan mempermudah dan memberikan informasi kepada setiap mahasiswa [4].

Perancangan Aplikasi E-informasi dan Jadwal Perkuliahan Berbasis Mobile Android". Dalam Penelitian ini dilakukan pengembangan sistem einformasi pada STIKOM Dinamika Bangsa Jambi. 
Sistem e-informasi digunakan oleh STIKOM Dinamika Bangsa untuk memberikan informasi jadwal perkuliahan dan informasi terbaru lainnya kepada mahasiswa. Dalam implementasinya, mahasiswa tetap harus ke kampus STIKOM untuk melihat jadwal kehadiran dosen. Dosen harus menginformasikan pembatalan jadwal kuliah ke bagian akademik. Dalam penelitian ini, penulis melakukan pengembangan aplikasi mobile Android yang dapat digunakan oleh dosen untuk melakukan pembatalan jadwal kuliah, dan dalam proses pembatalan tersebut akan mengirimkan notifikasi kepada mahasiswa sehingga mahasiswa menerima informasi jadwal perkuliahan lebih cepat. Berdasarkan pengujian, aplikasi ini dapat berjalan dengan baik menampilkan jadwal perkuliahan, informasi kampus serta notifikasi pada saat terjadi pembatalan jadwal kuliah [5].

Rancang Bangun SOA pada Sistem Informasi Geogragis Perijinan Pemerintah Kabupaten Lombok Barat. Dalam penelitian ini arsitektur SOA digunakan agar data pada Sistem Pelayanan Perijinan Terpadu (SPPT) dapat ditampilkan pada SIG Perijinan [6].

\section{METODOLOGI PENELITIAN}

Metode pembuatan aplikasi if-ku berbasis android terdiri dari beberapa tahapan yang digambarkan pada diagram alir berikut ini:

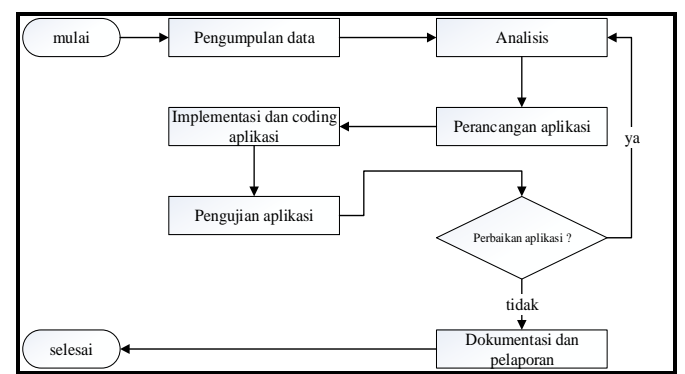

Gambar 1 Diagram alir metode pembuatan aplikasi.

\section{A. Pengumpulan Data}

\section{Studi literatur}

Studi literatur dilakukan dengan mempelajari dan memahami literatur yang berkaitan dengan penelitian. Studi literatur dilakukan dengan mempelajari buku-buku, literatur, jurnal serta mengakses beberapa situs terkait. Studi literatur berupa kajian pustaka beserta dasar teori yang terkait sistem informasi akademik berbasis mobile dan RESTful API. Dari hasil studi literatur dapat diketahui hal-hal teknis dan cara penyelesaian tugas akhir ini.

2. Observasi
Melalui teknik ini penulis melakukan pengamatan sistem yang sedang berjalan pada PSTI UNRAM. Berdasarkan observasi yang telah dilakukan, Saat ini di PSTI telah berjalan berbagai sistem informasi. Sistem- sistem tersebut antara lain sistem informasi nilai, Indeks Prestasi per semester, Indeks Prestasi Kumulatif, total Satuan Kredit Semester saat ini, total Satuan Kredit Semester lulus, mata kuliah, yang disebut Sistem Informasi Akademik (SIA) dan sistem informasi kehadiran dosen dan staff yang disebut sistem Fingerprint. Sistem Fingerprint yaitu sistem kehadiran dengan sidik jari. Permasalahan yang terjadi adalah Infromasi-informasi tersebut diakses melalui web browser dengan alamat yang berbeda-beda. Mahasiswa PSTI tidak mendapat informasi akademik secara real-time. Oleh karena itu, aplikasi yang dibuat akan menyediakan fitur pemberitahuan kehadiran staff Teknik Informatika, pemberitahuan nilai, serta pengumuman atau pemberitahuan yang menyangkut kegiatan perkuliahan melalui fitur group chat yang dapat memudahkan mahasiswa untuk mengetahui informasi-informasi perkuliahan secara real-time. Pengumpulan data akademik diantaranya data mata kuliah, data dosen, data mahasiswa, data nilai mahasiswa, dan data tahun akademik dilakukan dengan mengakses API milik SIA UNRAM.

\section{B. Perancangan Arsitektur Aplikasi}

Perancangan arsitekur dijadikan sebagai dasar dalam pengembangan sistem. Aplikasi yang akan dikembangkan adalah hybrid application sehingga dapat di- instal pada perangkat bergerak dengan sistem operasi Android. Android menyediakan platform terbuka bagi para pengembang untuk menciptakan aplikasi seperti aplikasi chatting, game dan aplikasi menarik lainnya [7]. Selain itu, akan dibangun aplikasi web sebagai pelengkap hybrid application yang hanya dapat diakses oleh admin. Aplikasi ini akan diimplementasikan di PSTI. Aplikasi meminta (request) dan memberikan (respon) data melalui web service. Dalam membangun aplikasi IF-KU, web service yang digunakan adalah rest web service. Pada arsitektur REST, data dan fungsi dianggap sebagai sumber daya yang dapat diakses lewat Uniform Resource Identifier (URI), biasanya berupa tautan pada web [8]. 


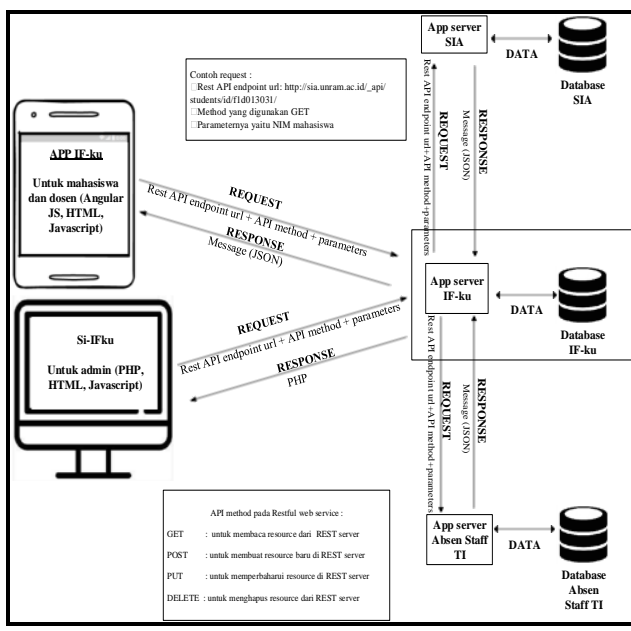

Gambar 2 Rancangan arsitektur sistem.

C. Usecase Diagram

Usecase menggambarkan proses yang dapat dilakukan oleh pengguna yang terdiri dari beberapa level di antaranya mahasiswa, dosen dan admin. Perancangan usecase dilakukan agar para pengguna mengetahui proses-proses apa saja yang dapat dilakukan di dalam sistem ini. Perancangan usecase dapat dilihat pada Gambar 3.

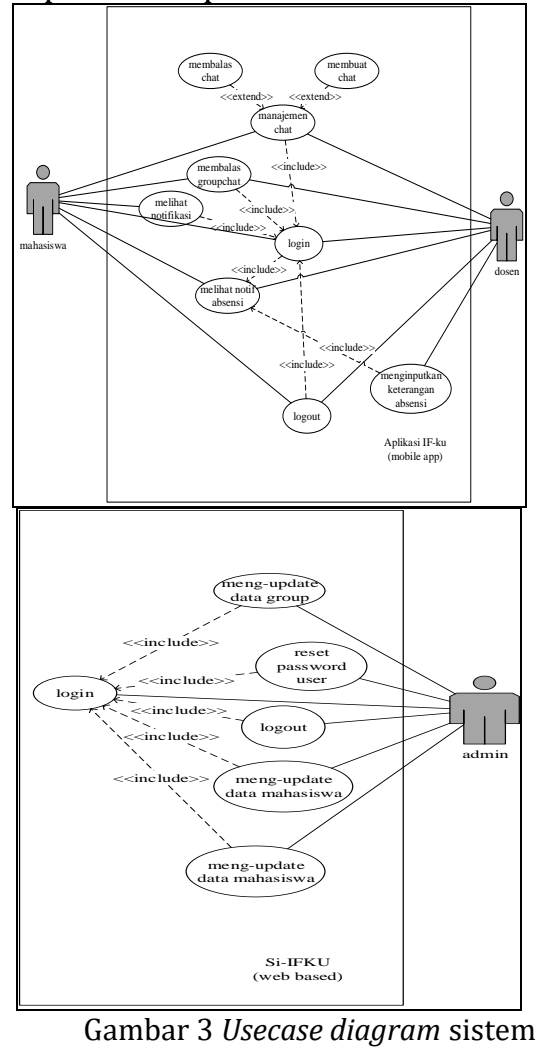

D. Perancangan Database

Tahap ini merupakan tahap perancangan database dimana, data-data yang ada pada sistem ini seluruhnya akan disimpan dalam satu database, sehingga data menjadi terintegrasi. Entity
Relationship Diagram (ERD) adalah pemodelan database yang terdiri dari entitas, relasi antar entitas dan atribut-atribut [9]. Perancangan database sistem dapat dilihat pada Gambar 4.

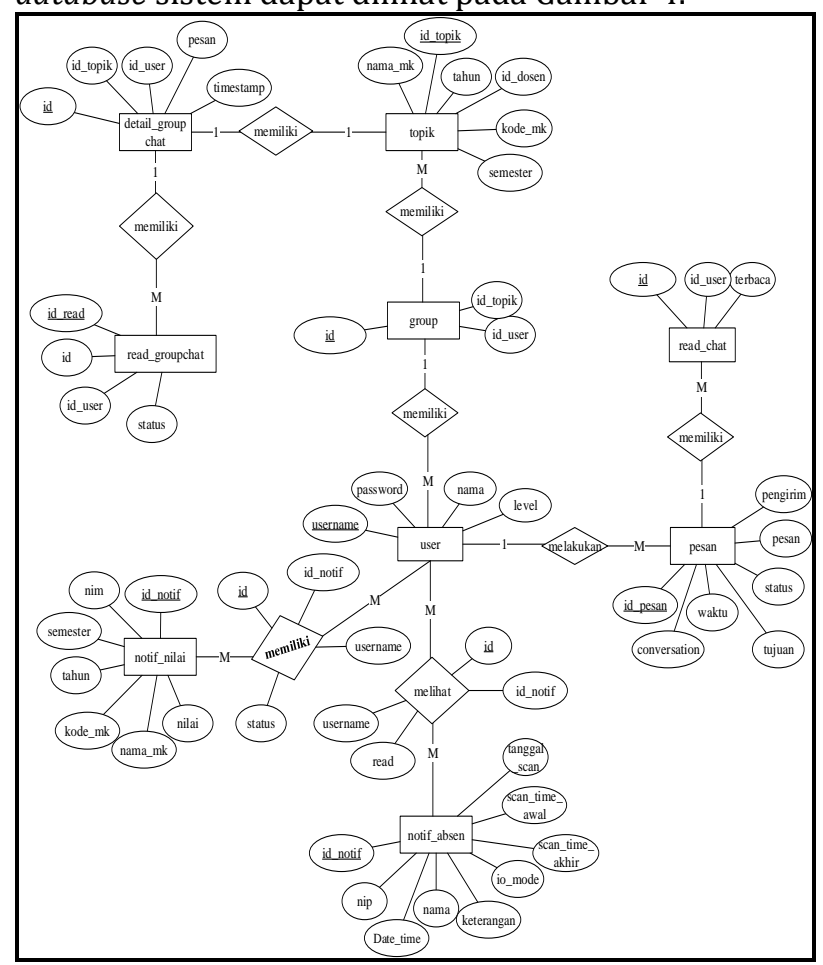

Gambar 4 Rancangan ERD aplikasi IF-ku.

\section{HASIL DAN PEMBAHASAN}

Berikut ini akan di bahas hasil dan implementasi sistem.

\section{A. Implementasi Interface}

Pada implementasi sistem terdapat beberapa tampilan interface sistem berdasarkan pengguna sistem ini yang terdiri dari beberapa level di antaranya mahasiswa, dosen dan admin. Berikut hasil dari implementasi interface dapat dilihat pada Gambar 5 sampai Gambar 8.

- Halaman user berisi data - data pengguna aplikasi IF-ku yang terdiri dari data username yaitu nip dosen dan NIM mahasiswa, nama dosen dan mahasiswa serta level pengguna yaitu dosen atau mahasiswa. Halaman user digunakan untuk mengatur ulang password penggguna aplikasi IF-ku. Untuk me-reset data user, admin harus menekan tombol reset password. Adapun interface halaman user dapat di lihat pada Gambar 5 berikut. 


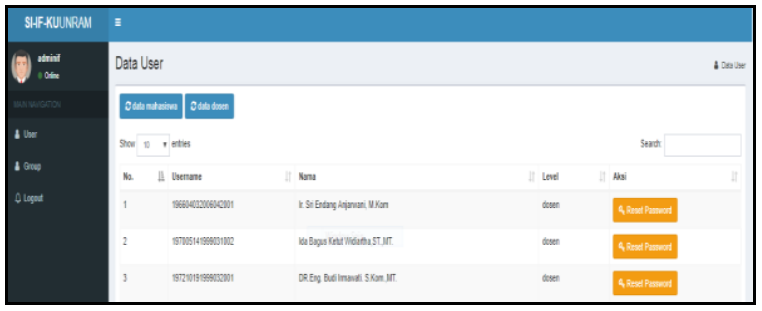

Gambar 5 Inteface halaman user pada sisi admin

- Halaman group berisi data - data group mata kuliah yang ditempuh mahasiswa tahun akademik saat ini beserta dosen pengampuhnya. Data-data yang ditampilkan terdiri dari data kode mata kuliah, nama mata kuliah, semester, tahun akademik, nip dosen, dan nama dosen. Adapun interface halaman group dapat di lihat pada Gambar 6 berikut.



Gambar 6 Inteface halaman group pada sisi admin.

- Halaman notifikasi berfungsi untuk memberikan informasi nilai mahasiswa sesuai data SIA Universitas Mataram secara realtime. Adapun interface halaman notifikasi dapat di lihat pada Gambar 7 berikut.

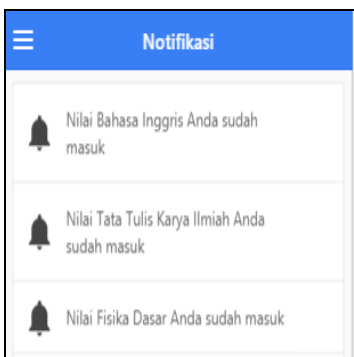

Gambar 7 Inteface halaman notifikasi pada sisi mahasiswa

- Halaman nilai berfungsi untuk menampilkan daftar nilai mahasiswa. Untuk menampilkan detail nilai, mahasiswa harus menekan salah satu nilai dari mata kuliah tersebut. Adapun interface halaman nilai dapat di lihat pada Gambar 8 berikut.

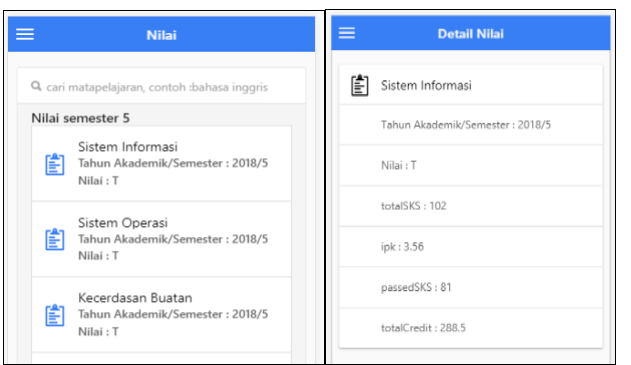

Gambar 8 Inteface halaman nilai pada sisi mahasiswa

- Halaman absen di sisi mahasiswa berfungsi untuk menampilkan daftar absen dosen dan staff TI sedangkan halaman absen di sisi dosen berfungsi untuk menampilkan daftar dosen dan staff $\mathrm{TI}$, pengingat absen dan memberi keterangan tambahan terkait absen. Adapun interface halaman absen dan edit keterangan tambahan dapat di lihat pada Gambar 9 berikut.

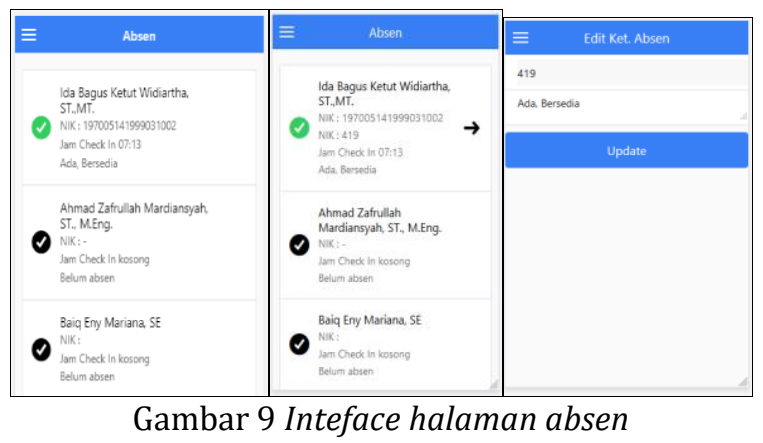

- Halaman pesan berfungsi sebagai media komunikasi pribadi antara sesama mahasiswa. Adapun interface halaman pesan dapat di lihat pada Gambar 10 berikut.

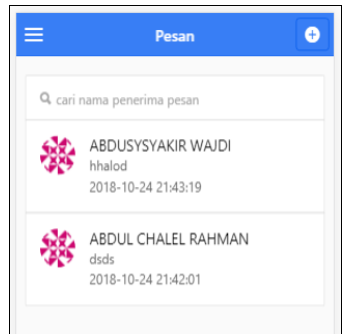

Gambar 10 Inteface halaman pesan pada sisi mahasiswa

- Halaman group chat berfungsi sebagai media komunikasi antara mahasiswa dan dosen, dimana group chat ini merupakan group chat mata kuliah yang ditempuh mahasiswa tahun akademik saat ini beserta dosen pengampuhnya yang secara otomatis terdaftar saat mahasiswa dan dosen login ke aplikasi. Adapun interface halaman group chat dapat di lihat pada Gambar 11 berikut. 




Gambar 11 Inteface halaman group chat

\section{B. Pengujian Sistem}

Pengujian sistem di lakukan menggunakan metode pengujian blask box dan kuesioner.

\section{Pengujian Black Box}

Pengujian black box digunakan untuk melihat kerbehasilan fitur-fitur di dalam sistem baik aplikasi mobile maupun aplikasi web seperti fungsi yang tidak benar atau tidak ada, kesalahan antarmuka, kesalahan pada struktur data dan akses basis data, kesalahan performansi, dan kesalahan inisialisasi dan terminasi [10]. Dalam hal ini, hasil pengujian menunjukkan bahwa semua fitur berhasil sesuai dengan harapan. Pengujian black box pada fitur aplikasi mobile terdiri dari login, notifikasi, nilai, absen, pesan dan group chat sedangkan aplikasi web terdiri dari login, user dan group.

\section{MOS}

Pengujian dengan menggunakan kuesioner dilakukan dengan mencari responden untuk mencoba menjalankan sistem, lalu memberikan pernyataan berupa kuesioner. Tujuan dari pengujian ini adalah mengetahui bagaimana kualitas sistem dilihat dari sisi pengguna.

Pengujian ini dilakukan oleh 30 responden di PSTI. Responden terbagi menjadi beberapa level yaitu admin, mahasiswa dan dosen. Tabel 2 merupakan daftar pentanyaan dan pembagian pertanyaan ke respoden untuk setiap level.

Tabel 2. Daftar pertanyaan.

\begin{tabular}{|l|l|l|l|l|}
\hline $\mathbf{N}$ & Pertanyaan & \multicolumn{3}{|l|}{ Responden } \\
\cline { 3 - 6 } $\mathbf{0}$ & & $\begin{array}{l}\text { A } \\
\text { D }\end{array}$ & $\begin{array}{l}\text { D } \\
\text { O }\end{array}$ & MA \\
\hline 1. & $\begin{array}{l}\text { Sistem ini mudah } \\
\text { digunakan? }\end{array}$ & $\sqrt{ }$ & $\sqrt{ }$ & $\sqrt{ }$ \\
\hline 2. & $\begin{array}{l}\text { Saya mengingat cara } \\
\text { penggunaan system } \\
\text { dengan mudah? }\end{array}$ & $\sqrt{ }$ & $\sqrt{ }$ & $\sqrt{ }$ \\
\hline 3. & $\begin{array}{l}\text { Saya dapat mengakses } \\
\text { fitur dengan cepat? }\end{array}$ & $\sqrt{ }$ & $\sqrt{ }$ & $\sqrt{ }$ \\
\hline 4. & Saya dapat memperoleh & & $\sqrt{ }$ & $\sqrt{ }$ \\
\hline
\end{tabular}

\begin{tabular}{|c|c|c|c|c|}
\hline & $\begin{array}{ll}\text { informasi } & \text { secara } \\
\text { realtime? } & \end{array}$ & & & \\
\hline 5. & $\begin{array}{lc}\text { Fitur yang ada sesuai } \\
\text { dengan } \\
\text { pengguna? }\end{array}$ & & $\sqrt{ }$ & $\sqrt{ }$ \\
\hline 6. & $\begin{array}{l}\text { Komposisi warna dan } \\
\text { peletakkan konten tidak } \\
\text { membingungkan? }\end{array}$ & $\sqrt{ }$ & $\sqrt{ }$ & $\sqrt{ }$ \\
\hline
\end{tabular}

Keterangan: AD: admin; DO: dosen; MA: mahasiswa.

Berdasarkan pertanyaan yang ada, responden diminta untuk menjawab dengan nilai-nilai tertentu antara lain:

1. 1 = Sangat tidak setuju (STS).

2. 2 = Tidak setuju (TS).

3. $3=$ Cukup (C)

4. $4=$ Setuju (S).

5. 5 = Sangat setuju (SS).

Selanjuntya akan dihitung persentase jawaban yang diberikan pengguna di setiap pertannyaan. Rumus untuk menghitung persentase nilai adalah sebagai berikut :

\section{Persentase : J / N * 100\%}

Keterangan:

J : total nilai jawaban responden pada setiap nomor.

$\mathrm{N}$ : Jumlah responden.

Dengan menggunakan rumus persentase, perhitungan hasil jawaban responden dapat di lihat pada Tabel 3, sedangkan grafik persentase jawabannya dapat dilihat pada gambar 9 .

Tabel 3. Hasil pengujian kuesioner.

\begin{tabular}{|c|c|c|c|c|c|c|c|c|c|c|c|}
\hline \multirow{2}{*}{ pertanyaan } & \multicolumn{5}{|c|}{ kategori jawaban } & \multirow{2}{*}{\begin{tabular}{c|} 
jumlah \\
responden
\end{tabular}} & \multicolumn{5}{|c|}{ persentase $(\%)$} \\
\hline & ST & \begin{tabular}{l|c}
$\mathrm{s}$ & $\mathrm{c}$ \\
$\mathrm{c}$
\end{tabular} & c & TS & STS & & ST & $s$ & C & TS & STS \\
\hline 1 & 13 & 17 & 0 & 0 & 0 & 30 & 43.3 & 56.7 & 0.0 & 0.0 & 0.0 \\
\hline 2 & 12 & 16 & 2 & 0 & 0 & 30 & 40.0 & 53.3 & 6.7 & 0.0 & 0.0 \\
\hline 3 & 8 & 15 & 7 & 0 & 0 & 30 & 26.7 & 50.0 & 23.3 & 0.0 & 0.0 \\
\hline 4 & 11 & 10 & 8 & 0 & 0 & 29 & 37.9 & 34.5 & 27.6 & 0.0 & 0.0 \\
\hline 5 & 7 & 21 & 1 & 0 & 0 & 29 & 24.1 & 72.4 & 3.4 & 0.0 & 0.0 \\
\hline 6 & \begin{tabular}{|l|l|}
6 & \\
\end{tabular} & \begin{tabular}{|c|c|}
15 & \\
\end{tabular} & 9 & 0 & 0 & 30 & 20.0 & 50.0 & 30.0 & 0.0 & 0.0 \\
\hline \multicolumn{7}{|c|}{ rata - rata } & 32.01 & 52.82 & 15.17 & 0.00 & 0.00 \\
\hline
\end{tabular}

Pengujian MOS digunakan untuk mengukur kesesuaian aplikasi berdasarkan pendapat subjektif dari pengguna Aplikasi IF-ku dimana jumlah keseluruhan responden sebanyak 30 orang. Responden terdiri dari 3 level yaitu admin, dosen dan mahasiswa. Persentase jawaban responden untuk setiap pertanyaan dapat dilihat pada gambar 9 . 




Gambar 12. Grafik persentase jawaban responden untuk setiap pertanyaan.

Dari gambar tersebut dapat dilihat bahwa sebesar $72,4 \%$ responden menjawab "setuju" pada pertanyaan nomor 5, sebesar 56,7\% pada pertanyaan nomor 1, sebesar $53,3 \%$ pada pertanyaan nomor 2. Berdasarkan gambar 9 persentase rata-rata jawaban responden dapat dilihat pada gambar 10 .

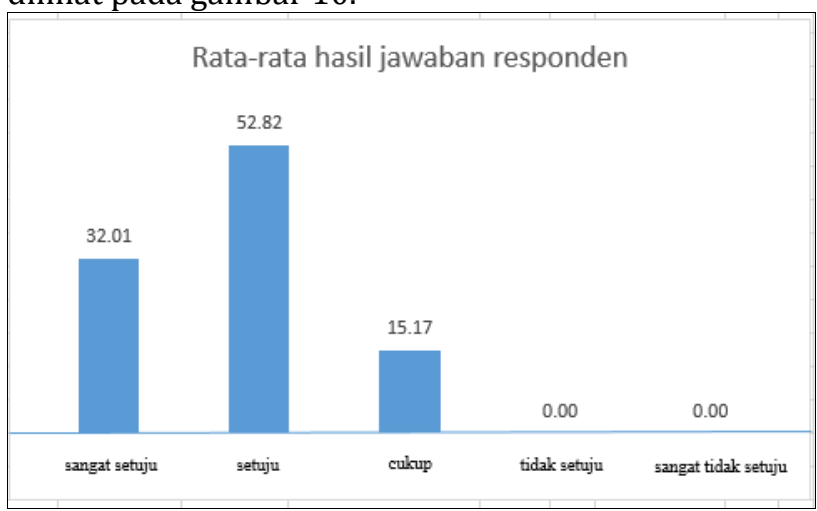

Gambar 13. Grafik persentase rata-rata jawaban responden.

Gambar 10 merupakan grafik rata - rata persentase jawaban responden. Berdasarkan hasil Mean Opinion Score (MOS) menunjukkan bahwa rata-rata penilaian responden bernilai 32,01\% + $52,82 \%=84,83 \%$.

\section{5. . KESIMPULAN DAN SARAN}

1. Kesimpulan

Berdasarkan penelitian dan pembangunan sistem yang dilakukan, terdapat beberapa hal yang dapat disimpulkan, antara lain :

$\checkmark$ Aplikasi ini dibuat dalam bentuk hybrid application, dimana mobile application dibuat menggunakan Framework Ionic dengan teknologi dan bahasa permrograman seperti HTML5, javascript, angularJs dan css. Kemudian, website dibuat menggunakan Framework CodeIgniter dengan teknologi dan bahasa permrograman seperti php, javascript dan css.

Aplikasi Mobile IF-ku dapat membantu memberi kemudahan bagi mahasiswa untuk mengetahui informasi-informasi akademik secara real-time sehingga penyampaian informasi menjadi optimal.

Dari hasil pengujian black box menunjukkan bahwa seluruh fungsi fungsi fitur aplikasi IF$\mathrm{ku}$ telah berjalan sesuai dengan sistem yang diusulkan.

Berdasarkan hasil Mean Opinion Score (MOS) menunjukkan bahwa rata-rata penilaian responden bernilai $84,83 \%$ setuju terhadap pengembangan aplikasi IF-ku.

\section{Saran}

Terdapat beberapa saran yang perlu disampaikan berdasarkan hasil pembahasan pembuatan Aplikasi IF-ku studi kasus Program Studi Teknik Informatika, yaitu : Untuk penelitian selanjutnya, peneliti bisa menambahkan fitur push notifications agar pengguna Aplikasi IF-ku dapat mengetahui notifikasi tanpa harus membuka aplikasi. Untuk pengembangan selanjutnya diharapkan dapat membuat aplikasi yang dapat berjalan di sistem operasi mobile lainnya seperti iOS maupun windows phone.

DAFTAR PUSTAKA

[1] M. Harmadya, G.M. Aryasasmita, dan N.K.A. Wirdiani, "Rancang Bangun Aplikasi Tryout Ujian Nasional Sekolah Menengah Pertama (SMP) Berbasis Android," Lontar Komputer, Vol.6 No.2, Agustus 2015.

[2] Fernalia, "Pembuatan REST Service SIMPEG API di kantor Walikota Bogor," Program Keahlian Manajemen Informatika Program Diploma Institut Pertanian Bogor, Bogor, 2015.

[3] P. Juwita, "Aplikasi Mobile Sistem Informasi Akademik Berbasis Android Pada SMKN 1 Pangkalpinang," Sekolah Tinggi Manajemen Informatika Dan Komputer Atma Luhur, Pangkalpinang, 2015.

[4] R. Putra, "Rancang Bangun Aplikasi Pengingat Jadwal dan Tugas Kuliah Berbasis Android," Sekolah Tinggi Manajemen Informatika Dan Komputer AMIKOM Yogyakarta, Yogyakarta, 2015. 
[5] A. Rahim, "Perancangan Aplikasi Einformasi Dan Jadwal perkuliahan Berbasis Mobile Android," Jurnal PROCESSOR, Vol.12 No.1, April 2017.

[6] I. Hadi, I.B.K. Widiartha, I.W.A.Arimbawa, "Rancang Bangun SOA pada Sistem Informasi Geografis Perijinan Pemerintah Kabupaten Lombok Barat," J-Cosine, Vol.1 No.1, 2017.

[7] D.W. Putra, A.P. Nugroho, dan E.W. Puspitarini, "Game Edukasi Berbasis Android Sebagai Media Pembelajaran Anak Usia Dini," Jurnal Informatika Merdeka Pasuruan, Vol.1 No.1, Maret 2016.

[8] E. Kurniawan, "Implementasi REST Web Service Untuk Sales Order Dan Sales Tracking Berbasis Mobile," Jurnal EKSIS, Vol.7 No.1, Mei 2014.
[9] A.S. Rosa, M. Shalahuddin, "Rekayasa Perangkat Lunak Terstruktur dan Berorientasi," Informatika Bandung. Bandung, 2013.

[10] M.S. Mustaqbal, R.F. Firdaus, dan H. Rahmadi, "Pengujian Aplikasi Menggunakan Blackbox Testing Boundary Value Analysis (Studi Kasus : Aplikasi Prediksi Kelulusan SNMPTN), " Jurnal Ilmiah Teknologi Informasi Terapan, Vol.1 No.3, 10 Agustus 2015 .

[11] Bagye, W., \& Najamudin, N. (2018). APLIKASI PENGHITUNG JUMLAH PAKAN SAPI POTONG BERBASIS ANDROID. Jurnal Informatika dan Rekayasa Elektronik, 1(2), 40-46. 